\title{
REGIONAL PLANNING FOR ACTIVE AND SUSTAINABLE SCHOOL TRAVEL: CHALLENGES AND OPPORTUNITIES
}

\section{By}

\author{
Caitlyn Flanagan \\ BAH, University of Waterloo, 2014 \\ A Major Research Paper \\ presented to Ryerson University \\ in partial fulfillment of the requirements for the degree of \\ Master of Planning \\ in \\ Urban Development
}

Toronto, Ontario, Canada, 2017

(C) Caitlyn Flanagan 2017 


\section{Author's Declaration}

I hereby declare that I am the sole author of this major research paper. This is a true copy of the major research paper, including any required final revisions, as accepted by my examiners.

I authorize Ryerson University to lend this major research paper to other institutions or individuals for the purpose of scholarly research.

I further authorize Ryerson University to reproduce this major research paper by photocopying or by other means, in total or in part, at the request of other institutions or individuals for the purpose of scholarly research.

I understand that my major research paper may be made electronically available to the public. 


\title{
REGIONAL PLANNING FOR ACTIVE AND SUSTAINABLE SCHOOL TRAVEL: CHALLENGES AND OPPORTUNITIES
}

\author{
(C) Caitlyn Flanagan, 2017 \\ Master of Planning \\ in \\ Urban Development \\ Ryerson University
}

\begin{abstract}
:
Significant efforts have been made worldwide to enable active and sustainable school travel, however there has been a lack of sustainable program success within the Greater Toronto and Hamilton Area (GTHA). This research begins to untangle the intricacies of integrating school travel programs into professional practice. A qualitative investigation was conducted in five municipalities that have implemented active and sustainable school travel initiatives within the GTHA. Participants from various sectors, including land-use planning, public health, and school boards, were selected for interviews. Thematic analysis revealed seven challenges that stakeholders confront, including Parent Acceptance, Regional Governance, School Boards, Program Ownership, Data Collection, Elected Officials, and Multidisciplinary Stakeholders. This research identified the ways in which stakeholders have attempted to overcome challenges offering insights into where additional resources, capacity-building, and improved planning procedures could be introduced. Identifying and resolving these challenges are pivotal to the success of future collaborative transportation planning in the GTHA.
\end{abstract}

Key Words: active and sustainable school travel planning, regional planning, thematic analysis 


\section{Acknowledgments}

This work was supported by Mitacs through the Mitacs Accelerate Program. The author would like to sincerely thank Dr. Raktim Mitra for supervising this research study within the TransForm Research Laboratory at Ryerson University. Without Dr. Mitra's vast knowledge of active and sustainable school travel planning and his genuine interest in the support and empowerment of graduate students - this work would not have been possible.

The author would also like to thank Jacky Kennedy and Kate Berry, from Green Communities Canada, for their ongoing interest in this work. Kate Berry, Senior Program Manager of Active and Safe Routes to School, contributed as the second reader for this research paper, providing value and guidance throughout the entire process.

Finally, the author would like to thank Jessica Stronghill and Jennifer McGowan (previously) from Metrolinx Smart Commute, Paul Young from Public Space Workshop, and Claire Basinski from MMM Group: a WSP Company, for their support, insights, and opportunities during this project. 


\section{Table of Contents}

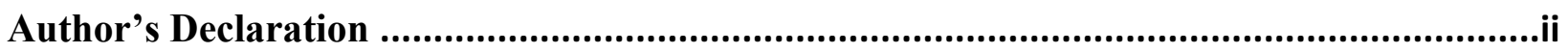

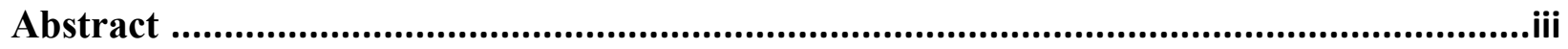

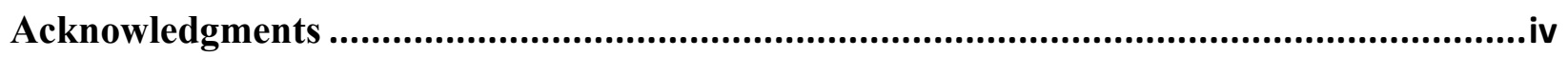

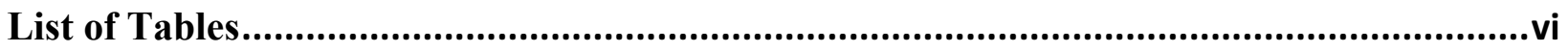

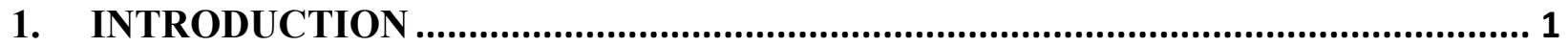

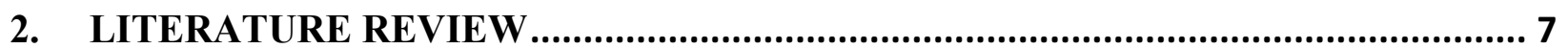

2.1 Understanding School Travel Planning (STP)................................................................................

2.2 Potential Impacts of School Travel Planning Programs..................................................................10

2.3 Best Practices in Regional ASST Planning ......................................................................................12

3. ASST PLANNING AND THE GREATER TORONTO AND HAMILTON AREA....16

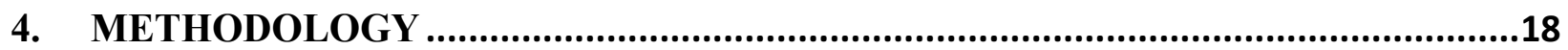

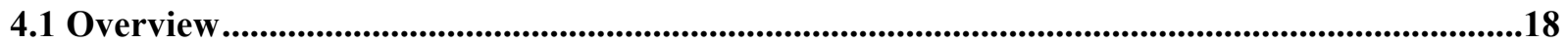

4.2 Participants .................................................................................................................................................18

4.3 Procedures and Instrumentation ..................................................................................................19

4.4 Analytical Approach .................................................................................................................................20

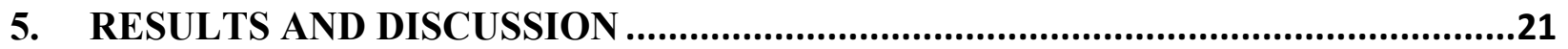

5.1 External Factors .....................................................................................................................................21

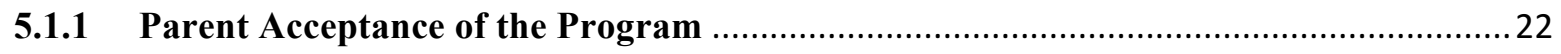

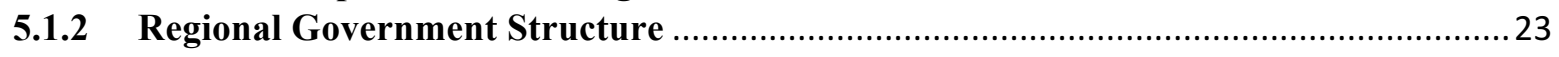

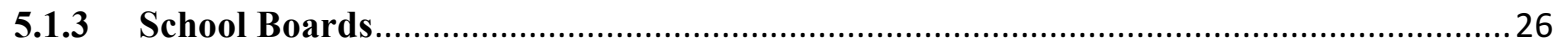

5.2 Internal Factors ………………………...............................................................................................2

5.2.1 Ownership by One Department or Organization ………………………………...2.

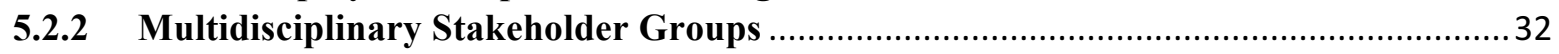

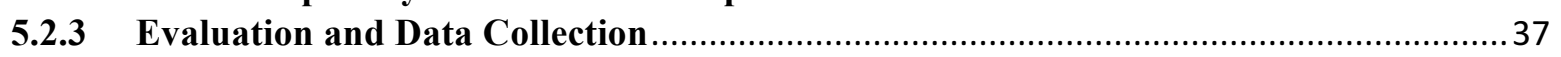

5.2.4 Engagement of Elected Officials............................................................................ 40

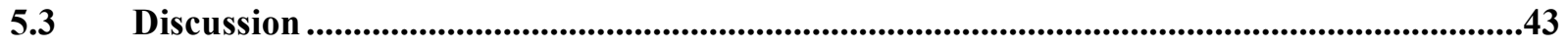

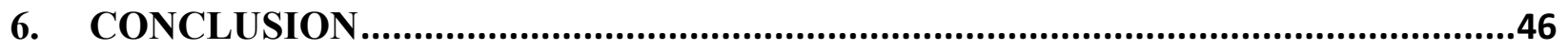

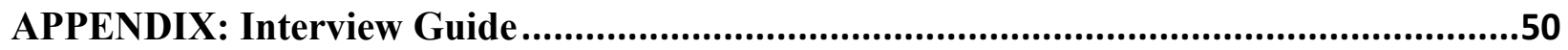

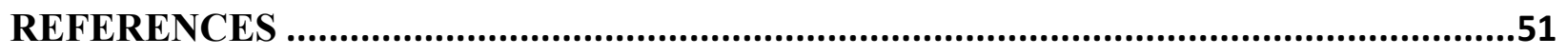

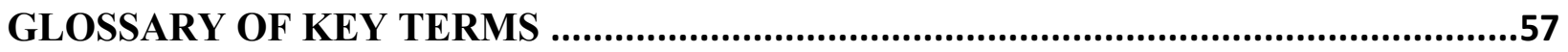




\section{List of Tables}

Table 6.1: Overview of Challenges and Opportunities...............................47 


\section{INTRODUCTION}

More children and youth in Canada, including those living in the Greater Toronto and Hamilton Area (GTHA), are now driven to and from school than ever before (Metrolinx, 2015a). This growing dependence on private automobiles for short trips is contributing to traffic congestion, and more importantly, negatively impacting the health and wellbeing of our youth population (Buliung et al., 2009; Janssen, et al., 2010; Larouche, 2012; Rennie, et al., 2006; van der Ploeg, et al., 2008). To maintain the health and safety of Canadian communities, an effective planning strategy is needed to inform policy and encourage programming that would improve rates of using active and sustainable modes of transportation for travelling to/from school.

This being said, planning for active and sustainable school transportation (ASST), particularly in the context of GTHA, can be complicated. Two-tier regional government structures, diverse collections of involved stakeholders, and the growing complexities of associated impacts on children and the environment have made policy and planning coordination not only increasingly necessary, but also increasingly difficult. Successful planning for ASST demands the coordination of stakeholders within each municipal jurisdiction to partake in regional-level planning. Many of these GTHA stakeholders already support ongoing, locallybased school travel initiatives, but have never collaborated with stakeholders from other municipalities on this topic. As effective transportation planning occurs at a cross-jurisdictional level and the benefits of ASST would positively impact all regional municipalities within the GTHA, it is critically important for stakeholders to work together and define common goals and develop measurement targets.

A regional approach to ASST planning is then imperative to build upon these current efforts and connect stakeholders. Regional planning offers opportunities for coordinating shared 
learning between practitioners, tracking and measuring regional progress in a systematic manner, and developing meaningful cross-jurisdictional programming and policy. To successfully leverage these opportunities, practitioners must be collaborative and proactive in identifying emerging opportunities, as well as flexible in overcoming challenges that might arise.

Government support and adoption is integral to the success of many notable international examples of regional ASST planning programs. In the U.S., the National Safe Routes to School (SRTS) program enables walking and bicycling school journeys, by dedicating more than 1.15 billion dollars towards the program by 2012 (National Center for Safe Routes to School, 2016). The funding is allocated through Section 1404 of the federal transportation bill, SAFETEA-LU, which is later distributed to individual state Department of Transportation (DOT)'s to implement programming and build appropriate infrastructure (Green Communities Canada, 2010). Further, the federal legislation regulates that $10-30 \%$ of total funds received must be used for noninfrastructure activities including public education and enforcement; with the remaining funds used for building infrastructure that improves the ability of students to walk and bicycle to school (Green Communities Canada, 2010). This centralized program may have contributed to significant decreases in child pedestrian injuries in several states, ranging from $25-73 \%$; benefitting upwards of six million students (National Center for Safe Routes to School, 2016).

Alternatively, Canada has introduced various Active to Safe Routes to School (ASRTS) and School Travel Planning (STP) programs, however many exist as ad-hoc initiatives, ranging in scale from regional, municipal, to individual-school level programs. The program was initially introduced as a pilot project in Toronto, Canada through a grant from the Toronto Atmospheric Fund (Green Communities Canada, 2010). Building upon momentum from the pilot's success, the leading organization - Green Communities Canada - received \$2.1 million from the 
Canadian Partnership Against Cancer and the Public Health Agency of Canada to expand and disseminate the STP program across Canada (Active and Safe Routes to School - About, 2017; Green Communities Canada, 2010). However, Canadian school travel related interventions are voluntary and primarily instigated by non-government and grassroots organizations, most of which do not have sustainable funding sources or access to data collection tools. The absence of sustainability and a systematic approach towards measuring progress has resulted in limited knowledge on the impact of past and ongoing Canadian initiatives (Buliung et al., 2009; Mammen, et al., 2014b).

Currently, the Regional Transportation Plan (The Big Move) for the GTHA, envisions that $60 \%$ of students will walk or cycle to school by 2033 (Metrolinx, 2008). Guided by this policy direction, Metrolinx, the regional transportation authority for the GTHA, has undertaken significant first steps towards building a coordinated strategy for ASST planning. Through partnership and funding from the Ministry of Transportation, Metrolinx created a provincial ASST Strategy Roadmap in 2013, informed by research, stakeholder interviews, and workshops. The Roadmap was crafted to establish the initial strategic goals and objectives for ASST planning in the GTHA, as well as other regions across Ontario (Metrolinx, 2013b). Outcomes from the Roadmap included the formation of the GTHA ASST Regional Hub: a network of school travel professionals and stakeholders across the GTHA that work towards implementing and promoting ASST interventions. To complement the Roadmap and provide deeper insights into the GTHA context, a comprehensive regional planning and consultation process was proposed and approved in early 2016.

The regional planning approach was initiated to develop an overarching framework to guide planning for ASST across the GTHA, as well as supporting municipal-level planning and 
facilitating local ownership within each of the upper and single tier regional municipalities. Currently, each GTHA regional municipality is at a different stage in planning for ASST, and there is a lack of collaboration or general strategy for advancement. As such, the regional approach has been designed to be adaptive, demonstrating flexibility in accounting for each regional municipality's specific needs, goals, and context. Further, the proposed planning process and identified outcomes will be specific to each regional municipality. The primary objectives of developing a regional approach to ASST in the GTHA include, 1) establish a baseline of school travel status in each regional municipality; 2) determine opportunities and challenges to ASST; 3) develop a customized set of overarching objectives and priority initiatives; 4) set regional-level targets; and 5) determine how to best collect and track data, as well as identifying next steps for each regional municipality (Flanagan and Mitra, 2016). Metrolinx has provided funding, strategic direction, and the appropriate facilitation and educational support to equip stakeholders in progressing the GTHA regional planning process, however, the final objective of the process includes each regional municipality leading and maintaining local ownership over its customized ASST action plan.

When considering the need for an adaptive ASST regional planning process in the GTHA, it is critical to recognize this proposed approach is not without its associated challenges. Identifying, resolving, and overcoming these challenges are pivotal to the success of all forms of regional collaborative planning. The Ontario ASST Roadmap has provided multiple opportunities towards achieving goals listed in The Big Move, however many challenges towards successful implementation of a regional strategy remain. Progressing and improving the regional ASST planning strategy, under the overarching goals of the provincial ASST Roadmap, 
will provide solutions and direct means for efficiency in coordination, monitoring, evaluation, and the potential for sustainable funding.

This study contributes to ongoing ASST planning strategies by exploring and gaining a deeper understanding of the overarching opportunities and challenges that may emerge while introducing a regional-level planning approach. This research will provide practitioners and policymakers with a clearer narrative of the current state of ASST planning in the GTHA, so that ongoing regional strategy can directly address the identified challenges and facilitate additional opportunities. Moreover, the study will examine relationship dynamics between stakeholders to identify gaps in planning, barriers to implementation, as well as exploring facets of ASST planning that would benefit from further support by the Metrolinx and the provincial ASST Roadmap. More broadly, findings from this research will provide valuable insights to inform other jurisdictions, within countries that lack national programs, that are embarking on similar regional planning approaches.

This paper is organized into three key sections. First, the literature review establishes the context of current approaches to planning for ASST; considering and exploring different interpretations of the initiative (Chapter 2.1), discussing international outcomes of school travel planning programs (Chapter 2.2), and reviewing a recent jurisdictional scan of best practices in regional planning for ASST (Chapter 2.3). As there is limited academic literature on the specific professional challenges and opportunities faced by ASST stakeholders, the review aims to shed light on obstacles that other researchers and institution-led ASST programs have encountered when conducting pilot projects and studies.

In Chapter 3, the research then turns to the current state of planning for ASST in the GTHA, revealing the contextual interpretations of school travel planning, as well as addressing the 
present gaps in the planning process and identifying areas that could be reinforced by a regional planning approach. Chapter 4 illustrates the methodological approach used for this study.

Finally, in Chapters 5 and 6, the research discusses key findings reported from a qualitative interview process with GTHA ASST stakeholders, reframing the discussion into a contextspecific assessment of professional challenges and opportunities in planning for ASST at a regional scope. Explored through a collection of seven external and internal themes, the discussion reveals the distinct challenges that stakeholders confront, drawing insight into where additional resources, capacity building, and improved planning procedures could be introduced. 


\section{LITERATURE REVIEW}

The concept of ASST, or AST (active school travel) as it is frequently referred to, originated from a growing concern among researchers and community organizations that increased vehicular travel presents health and wellbeing concerns for children (Buliung et al., 2009; Janssen, et al., 2010; Larouche, 2012; Rennie, et al., 2006; van der Ploeg, et al., 2008), as well as detrimentally affecting the ecological quality (Wilson et al., 2007) and level of safety within communities (Rothman, et al., 2013). To address the dominance of vehicular travel in municipalities across the Western World, studies have examined a range of potential reasons that may deter students from engaging in ASST. In response to these trends, formal school travel planning programs have gained global momentum. The following review explores the School Travel Planning process, potential impacts of school travel planning, and international best practices.

\subsection{Understanding School Travel Planning (STP)}

In recent decades, there has been a significant decrease in students walking and cycling to school in several nations, including Canada (Baslington, 2008; Buliung et al., 2009; Hinckson, et al., 2011; McDonald et al., 2009; Weigand, 2008). This trend has been mirrored by a rise in the number of students travelling to school by car (Buliung et al., 2009; Baslington, 2008). From 1986 to 2011 the GTHA reported a 10\% decrease in elementary students walking to school (Buliung et al., 2009; Metrolinx, 2015a;). These daily, short automobile trips for school travel are directly contributing to the ongoing congestion issues throughout the GTHA, in addition to reduced levels of physical activity in school children (ParticipACTION, 2016)

School Travel Planning was introduced in response to this trend by addressing concerns related to congestion, safety, community health, and the environment through locally 
implemented initiatives (Peddie and Somerville, 2005). Introduced as a national program in the United Kingdom between 1997-1998 (Atkins Limited, 2010), formal school travel planning programs have gained significant support and momentum around the world. Programs have been conceived under a variety of names and scales, however, each fundamentally seeks to increase active commuting, decrease car dependence, and promote the road safety of school children. Within Canada, school travel planning was adopted by Green Communities Canada in Ontario and has quickly gained traction across the entire country, as well as attracting media and political attention.

School travel planning is not designed to be one size fits all, but rather takes a multidisciplinary and school-specific approach towards engaging stakeholders, as well as discussing and evaluating school travel issues (Mammen, et al., 2014a). This practice encourages community-wide involvement to collaborate and intervene on ASST barriers (Mammen, et al., 2014b). Multiple involved stakeholders and partners increases the likeliness of the school travel planning reaching, engaging, and resonating with larger proportions of the community (Ward, et al., 2007).

This process aims to create customized 'school travel plans' - comprehensive strategy documents that assess current barriers to ASST and uses the information to develop an action plan to tackle local concerns and achieve school-specific goals (Metrolinx, 2012). School travel plans exist as living documents and are collaboratively written by involved stakeholders. The documents are viewed as a mechanism for organizing a range of school travel initiatives and/or interventions, and therefore cannot be implemented in isolation (NICE, 2008). School travel plans are comprised of four distinct types of ASST interventions for schools to utilize: education (e.g., workshops and awareness materials), activities/events (e.g., programming), capital 
improvements (e.g., built environment improvements including bike lanes), and enforcement (e.g., crossing guards and increased police presence) (Buliung, et al., 2011, Mammen, et al., 2014b).

Recent reports indicate that school travel plans can be a cost-effective and feasible ASST intervention (Metrolinx, 2014). In Canada, school travel plans are implemented by an appointed school travel plan facilitator whom leads a five step process. First, 'Set Up', allows stakeholders to develop a time frame, identify goals, and create an evaluation framework. Second, 'Assess Conditions' is conducted to collect baseline levels of mode choice and safety concerns. Third, 'Action Planning'. During this step an action plan is created and is divided into five sections (engineering, education, enforcement, encouragement, and evaluation). The fourth step, 'Implementation' involves the collection of follow-up data, and lastly, 'Monitoring and Improvement' includes the practice of conducting ongoing evaluation of ASST interventions (Hinckson, et al., 2011; Metrolinx, 2012).

Regardless of the effort and dedication placed into formal planning for school travel, communities will continue to contend with societal challenges including rising traffic congestion and car ownership (Cairns et al., 2006), as well as sprawling, low density community planning which is not conducive to walking and cycling to/from school (Mitra, et al., 2014; Mitra, et al., 2015; Schlossberg, et al., 2006). Recommendations from School Travel Planning programs can include improvements for the built environment, offering tangible solutions that are both context-specific and encourage infrastructure investment that direct fulfills the needs of each school and surrounding school zone (Cairns, et al., 2006). Recent research has found that the visible presence of active transportation infrastructure is positively associated with active school travel (Mitra, et al., 2014, Schlossberg, et al., 2006; Timperio, et al., 2006), however such capital 
improvements particularly aimed at walking and cycling for school transportation, are limited or nonexistent in a Canadian context, particularly due to the lack of centralized longer term funding commitments from the province or the municipalities.

Studies have shown that a key feature of well-developed school travel programs is a positive relationship between local authorities, supportive teachers, and other stakeholders. Identification of a champion, involvement of children, introduction of school travel policies, presence of cycling and walking infrastructure, and extensive safety measures are also important factors (Cairns, et al., 2006, 2006; Metrolinx, 2012). These identified features, guided by the strategic direction of the larger school travel planning process, is implemented by stakeholders through the use of ASST interventions.

\subsection{Potential Impacts of School Travel Planning Programs}

There is limited literature that has discussed the outcomes of school travel planning and related programming. Researchers have noted the difficulty in systematically evaluating school travel planning programs as it does not fit into conventional transportation frameworks, and produces ranging impacts that are difficult to quantify (Mackett, et al., 2003).

Despite limited scholarly literature, one study based in California, US, generally deduced that children who are involved with school travel planning programs are potentially more likely to walk and cycle to school than children who are not (Boarnet, et al., 2005).

In a 2011 GTHA study, researchers found a modest increase of ASST from $43.8 \%$ to 45.9\% (Buliung, et al., 2011), indicating that ASST interventions are feasible and moderately effective in encouraging students to walk and cycle to school. Researchers determined that the three most effective school travel-based interventions were education (specifically: safety awareness), activities/events, and capital improvements (Buliung, et al., 2011). The more recent 
Canadian evaluation of national school travel planning interventions found $17 \%$ of the sample self-reported less driving (Mammen, et al., 2014b).

Hinckson, et al. (2011) conducted an evaluation of regional-level ASST interventions within Auckland Region in New Zealand. A moderate increase in ASST levels (40.5\% to 42.2\%) over the course of three years was found (Hinckson, et al., 2011). The study indicated that travel behaviour is difficult to change, and the community required three years for ASST to become incorporated into daily mode choices. The study provided evidence that regional-level school travel planning interventions can increase ASST levels in students, however it requires the strong support of committed stakeholders (Hinckson, et al., 2011).

Current literature has demonstrated the benefits and challenges associated with both school-specific interventions, and those with a broader focus, including national accreditation or achievement initiatives. Some researchers have suggested that future ASST interventions should be scaled-up to a larger scope (Buliung, et al., 2011), while other researchers state schoolspecific interventions are significantly more effective (Chillon, et al., 2011; Weigand, 2008). Chillon and colleagues conducted a systematic comparison of ASST interventions, concluding that existing efforts to promote active school travel are widely heterogeneous in size, scope, and focus; and this presents difficulties when comparing for effectiveness (Chillon, et al., 2011). However, the researchers did find that ASST interventions that produced the greatest increase in ASST levels were found to share two common elements: 1) strong involvement of schools with principals and teachers working together to implement the intervention, and 2) families receiving school-specific materials with consistent encouragement to walk/cycle to school (Chillon, et al., 2011). 
Overall, the current literature examining the impacts of planning for school travel has shown that the diverse assortment of ASST interventions have evidenced small, yet, promising effectiveness in encouraging children to walk and cycle to school (Buliung, et al., 2010; Chillon, et al., 2011, Mammen, et al., 2014b).

\subsection{Best Practices in Regional ASST Planning}

Regional planning for ASST has been internationally championed, offering many best practices and key learnings that can be applied to other regions interested in establishing a coordinated program. In a recent case study research, we analyzed four regional examples from four countries: Greater Manchester, the United Kingdom; Auckland Region, New Zealand; the Bay Area Region, U.S., and Metro Vancouver, Canada (Flanagan and Mitra, 2016). The research identified international similarities and differences in school travel policy, programming, and planning efforts.

\subsubsection{Policies and Funding}

Clear commitment from regional or national government, through policy statements in legislation or the creation of an individual active transportation plan that highlights school travel, were common across case study regions (Flanagan and Mitra, 2016). The United Kingdom has made notable advancement in school travel planning due to a clear policy mandating the development and ongoing monitoring of school travel plans in all schools (Education Act and School Inspections Act, 1996). Government policy directs and demands the progression and sustainability of school travel programs, strengthening its impact and ability to reach more members of the community. Effective policy statements are often complemented by detailed action strategies - securing commitment from involved stakeholders, dividing tasks, setting 
priorities, and maintaining accountability to the school travel program (Flanagan and Mitra, 2016).

Regional ASST programs were found to be implementable when ownership of the program was undertaken by one major stakeholder, commonly the regional transportation authority (Flanagan and Mitra, 2016). Notably within the Bay Area Region, US, many small notfor-profit groups had built a strong community presence by coordinating local school travel planning initiatives. These district-level programs created the foundation for public acceptance and stakeholder buy-in, however faced precarious and unsustainable financing through microgrants and environmental funds (Flanagan and Mitra, 2016). The Metropolitan Transportation Commission, the Bay Area Regional Transportation Authority, intervened to scale-up the program towards a centralized, regional model, yet continues to build upon and support the local community efforts (Metropolitan Transportation Commission, 2017). Consistent and stable ownership is typically associated with sustainable funding sources, providing opportunities to create more significant outcomes in the region. Grants, fee-for-service, and government allocation are examples of diverse funding strategies that were successful in the differing regional contexts of each case study (Flanagan and Mitra, 2016).

\subsubsection{Stakeholders and Champions}

Connectedness and collaboration between stakeholders is fundamental to regional ASST planning. To coordinate and sustain collaboration, each case study region maintains an interactive, informative, and centralized website (Flanagan and Mitra, 2016). These websites act as online hubs to connect ASST planning professionals to maintain ongoing communication, celebrate successes, and share key learnings from failures. For example, Metro Vancouver's website, developed by HASTe BC, offers an 'active showcase map' that features all participating 
schools in the region, as well as displaying each individual school's objectives and progress to date (HASTe BC, 2017).

Engaging a broad stakeholder group, with representatives from the private, public, and not for profit sectors, have been noted as a key practice from many of the case studies. This strategy provides opportunities for collaborative planning, a range of perspectives, and additional sources for human and financial capital (Flanagan and Mitra, 2016).

Identifying a champion for regional ASST planning is critical when engaging stakeholders, so that continuity and progress is sustained. Each regional case study has identified a clear leader in progressing planning efforts, ranging from national government to an exceptionally active not-for-profit organization. Additional benefits of ownership include consistent messaging and programming, sustainable funding by one dedicated source, as well as opportunities for longitudinal data collection and informing policy statements. The Bay Area region has uniquely championed this practice by maintaining ownership of the program by regional transportation authority within the public sector, completing evaluations and strategic planning with private sector consultancy firms, and empowering not-for-profits to lead local implementation and community engagement (Flanagan and Mitra, 2016).

\subsubsection{Initiatives and Data Collection}

All four case studies have effectively utilized centralized incentive programs to attract new schools to participate, collect substantial data on progress and potential improvements, and illustrate ASST planning as an enjoyable, yet systemic, program. Auckland Region has leveraged this practice by introducing the WoW (Walking and Wheeling on Weekdays) game: a data collection method that requires students to post when they have travelled to school in an active way (TravelWise Schools, 2017). The game requires entire classes to participate, and facilitates 
competition between classrooms, schools, and districts to win trophies and awards (TravelWise Schools, 2017). This method has demonstrated significant success in collecting data on children travel patterns (Auckland Transport, 2013). In addition to data collection on travel patterns, researchers found it is vitally important to routinely evaluate the programming initiatives to ensure they are relevant and attracting students. Auckland Region reaches out to students and teachers to assess incentive initiatives, providing them with opportunities to design better programming, thus collecting better data (Flanagan and Mitra, 2016). Ongoing evaluation of data collection methods, programming, and initiatives preserves the collaborative nature of ASST planning - encouraging accountability, transparency, and fostering greater impact with communities as students and families feel included in the dialogue. 


\section{ASST PLANNING AND THE GREATER TORONTO AND HAMILTON AREA}

The Greater Toronto and Hamilton Area (GTHA) is Canada's largest urbanized region, with more than six million people. The region includes a large student population that is served by over 1,500 elementary schools (Metrolinx, 2012). Upon completion of Green Community Canada's original STP pilot project in the City of Toronto, ASRTS programming was expanded throughout the GTHA by 2000, and across Canada by 2012 (Metrolinx, 2012). In 2009, Metrolinx collaborated with Green Communities Canada to conduct the 'Stepping It Up' pilot project, using the Canadian STP model (Metrolinx, 2012). The project ran from 2009-2011, receiving funding from Transport Canada's ecoMOBILITY program (Metrolinx, 2012). The pilot project, delivered at 30 elementary schools (Metrolinx, 2012), brought together a diversity of stakeholders to identify key opportunities in supporting ASST across the GTHA.

That being said, participation in ASST planning in Canada remains completely voluntary and primarily promoted by grassroots organizations (Mammen, et al., 2014b). Through the collaboration with Metrolinx, ASST programming within the GTHA has sustained with a gradual, however systematic, series of School Travel Planning projects and initiatives. Metrolinx has built upon ongoing efforts in ASST planning by introducing a regional campaign for cycling called 'Bike to School Week'. This campaign recorded participation from 144 GTHA schools and 16, 225 students, resulting in 79\% more students biking to school than usual during the week-long event (Metrolinx, 2015b). Despite positive outcomes in local interventions, Metrolinx reported only $11 \%$ of surveyed GTHA parents were aware of ASST planning programs in their area (Metrolinx, 2013a).

Metrolinx has begun the process of coordinating a regional approach to ASST programming by hosting the GTHA ASST Hub, however, the lack of explicit planning strategies 
for ASST has resulted in inconsistent implementation among GTHA municipalities. In 2003, the municipality of Aurora (York Region) approved a 'school travel planning' policy intended to encourage physical activity, alleviate school related traffic congestion, and reduce greenhouse gas emissions (Aurora Infrastructure \& Environmental Services, 2013). Aurora's dedication to active and sustainable transportation is one of the few examples of a GTHA municipality taking a leadership role in ASST planning. Many regions have demonstrated difficulties when implementing ASST planning due to limited stakeholder interest and inadequate infrastructure. The GTHA's residential landscape encompasses a great diversity of urban form, ranging from rural to suburban to inner-urban. These different neighbourhoods have distinct challenges relating to active transportation, further hindering municipal commitment. 


\section{METHODOLOGY}

\subsection{Overview}

To gain a deeper understanding of the opportunities and challenges that may emerge while introducing a regional-level ASST planning approach, this research presents a thematic analysis of qualitative data collected from a small number of key informants across the GTHA to explore its key research questions. Thematic analysis includes a process of induction that involves the identification and organization of themes arising from raw data (Coffey, et al.,1996). Qualitative research is appropriate for this study as the methodology will collect rich data on complex multidisciplinary topics, such as ASST planning, and is easily adapted and scaled to the varying local contexts and conditions of participants (Marshall, et al., 1989). The research design is responsive and flexible, and can appropriately be re-analyzed for cross-case comparison analysis. Further, qualitative research can effectively yield insights into idiographic causation, recognizing that each ASST planning professional plays varying roles in the program and experiences different challenges and opportunities (Marshall, et al., 1989).

\subsection{Participants}

To answer the study's research questions, it is pivotal that all participants are directly involved and/or informed of ASST planning, and have acquired the appropriate experiences and knowledge on the issue in the GTHA. As a result, we used a purposive sampling approach when selecting participants for this study (Nueman \& Robson, 2012).

Complete lists of suitable participants were provided by key contacts in the following GTHA regional municipalities: Toronto, Hamilton, Peel Region, York Region, and Durham Region. Halton Region declined to participate in the interview process on the basis that it was unhelpful to their approach towards regional planning for ASST. A key contact is generally 
defined as an interim champion in ASST planning, and usually contributes to the coordination of a municipal or regional steering committee focusing on ASST planning, if established. The key contact, in collaboration with their respective steering committee, identified 3-10 key stakeholders to be interviewed. Following that, participants were categorized into one of three main categories: (1) they are actively involved in ASST planning, (2) they are engaged in ASST planning but do not actively contribute, or (3) they are relevant to ASST planning.

Participants were selected based on their level of involvement within the current planning process, with preference given to individuals with higher levels of seniority. Further, the researchers attempted to select a diverse array of participants from varying professional occupations. The final selection of participants including 17 individuals, comprised of: six transportation and municipal planners, five public health professionals, two not-for-profit professionals, two school board representatives, one trustee, and one member of a student transportation consortia.

\subsection{Procedures and Instrumentation}

Semi-structured interviews were conducted with the planning professionals over telephone, approximately 3-5 per municipal region. The participants were asked a set of 14 semistructured questions (plus additional prompt questions) focusing on - (1) Roles and Responsibilities, (2) Current Practice and Processes, and (3) Stakeholder Relationships. Due to the nature of the research questions, formal ethics approval by the Ryerson University Research Ethics Board was not required for this study.

Participants were pre-informed about the project by the key regional contact, and subsequently emailed by the researcher with a participation invitation. The invitation included a brief background on the project and explanation of the interview's purpose, as well as providing 
the background document of past ASST and School Travel Planning efforts in their municipal region created by Green Communities Canada. A broad list of key questions was also provided at that time. The researcher found that it was appropriate to provide the key questions in advance to allow the participant to prepare for the interview, and acquire necessary and factual information. These interviews were audio recorded and subsequently transcribed verbatim. Interview lengths ranged from 30 to 60 minutes.

\subsection{Analytical Approach}

To organize the "often messy and unpredictable nature of qualitative research" (Darbyshire et al., 2005), all collected data were thematically analyzed for significance and patterns (Nueman \& Robson, 2012). Transcriptions were reviewed multiple times, and key statements considered significant were identified. The key statements were deconstructed for deeper analysis and compared with other key statements for similarities and differences (Biddix, 2009). Following this, key statements were grouped into categories of the same thematic significance. This process identified central phenomenon, causal conditions, and the social context and associated effects (Biddix, 2009). Lastly, selective coding was undertaken to isolate the distinct themes that demonstrate challenges and opportunities in ASST planning. This process of coding organized the information into a data table that clearly exhibited how the researcher connected and compared the categories together to form conclusions (Glaser \& Strauss, 1967). 


\section{RESULTS AND DISCUSSION}

This chapter describes the challenges and opportunities that may emerge when engaging in regional ASST planning, using data collected through qualitative interviews of various stakeholders relevant to ASST planning practice in the GTHA. These findings specifically pertain to the GTHA, however, they have been discussed within a flexible narrative format, and provide thematic insights that could be potentially applicable to other Canadian regions.

This chapter has been divided into two sections: External and Internal factors. External factors are described as forces that exist outside of the immediate regional ASST planning process. Following this, Internal factors are discussed, which are defined as dynamic forces that directly emerge within regional ASST planning. Challenges and opportunities relating to each factors are further categorized into several themes, based on what study participants have experienced while planning for ASST.

\subsection{External Factors}

The following themes illustrate the multifarious factors that affect regional ASST planning and initiatives. External factors are the results of the greater community and forces that exist outside the scope or authority of regional ASST planning professionals. The examined themes include: 1) Parent Acceptance of the Program; 2) Regional Government Structures; and 3) School Boards. External factors affecting ASST planning have been previously examined in international research, these factors are only briefly discussed in this report to provide/ compare the perspective of study participants. The process of introducing and integrating planning for regional ASST into transportation planning practice is highly affected by societal externalities. These factors exist either outside the control and influence of regional ASST stakeholders, or are exceedingly difficult to overcome. 


\subsubsection{Parent Acceptance of the Program}

Engaging the parent community and/or developing acceptance of programming among students' households is a critical challenge for ASST planning. Perceived fears of allowing children to walk alone, coupled with an age of convenience relating to car-dependence, may have contributed to a strong reliance on vehicles for daily school journeys (Buliung, et al., 2009;

Mitra, et al., 2014; Metrolinx, 2012). Further, engaging parents in the planning and programming can be challenging as they do not exist as a centralized body. Study participants discussed that parent committees are the only means towards reaching parents, yet, these committees represent only a small group of patents who are already interested and involved. Moreover, attempting to engage more of the parent population can risk polarizing a school community, causing argumentative dialogue, and fostering an attitude of parent-shaming on families who continue to drive their children to school.

Despite presenting multi-faceted challenges, gaining parent acceptance is essential for progressing and gaining momentum within regional ASST planning. Parents potentially represent the most important stakeholder in the discussion of child mobility as they are the keepers of children, as well as key decision makers related to a child's day-to-day travel needs. Without the trust and buy-in from parents, all study participants agreed that regional ASST planning work cannot continue sustainably: "Challenges occur when overcoming some of the perceptions out there that parents and people in general have about walking being unsafe. Often they are pointing to the piece around crime... And how do you fight the whole time crunch that people are feeling? As much as we try to make policy and change the environment to make choosing to walk the easy choice, if people still see the barrier with safety and time, that is a huge challenge". 
Opportunities for increasing parent acceptance, as noted by study participants, include the development of new engagement methods that involve them as an equal stakeholder within the planning process. This includes new approaches in stakeholder discourse and education interventions. One study participant expressed that ASST dialogue should be framed as a shared community problem, instead of placing blame entirely on the parents. By doing this, the discussion expands the benefits and ownership of ASST onto all residents, and parents could be more willing to cooperate if they are not longer villainized. Further, educating parents about the compounding individual and societal benefits of ASST, identifying specific parent fears, and creating programming tailored to them is highly important. One study participant pointed out, "We need to take that into consideration - their fears are genuine fears. If you have parents that are afraid that their kids are going to get kidnapped by a stranger, the committee might say 'that is ridiculous, it isn't going to happen' - but to the parents it is a real threat". Participants noted faith based groups, kindergarten registration, and youth conferences as possible engagement opportunities.

\subsubsection{Regional Government Structure}

The GTHA is comprised of six single tier and regional municipalities, many of which are further divided into upwards of nine individual municipalities. The regional municipalities, commonly referred to as 'upper-tier' municipalities, provide common services to each of its associated, 'lower-tier' municipalities. As such, regional planning for ASST in the GTHA is being approached as a flexible and adaptive proposal to accommodate this spatial hierarchy, however, significant challenges towards implementation and coordination are expected to persist.

Between lower-tier municipalities, it is common for each to have different policies, plans, and regulations that define organizational protocol and priority. These differences present 
challenges for regional ASST planning as professionals are required to navigate and comprehend conflicting mandates. Study participants discussed that since each municipality works differently, they are required to spend the majority of their ASST planning-dedicated time towards adjusting communication messaging and liaising with new stakeholders: "It would be much easier...if there was a consistent format across the region. Each municipality has their own fire department for example, so there are different interpretations. We always have to deal with all three and find consensus, and sometimes, there is no consensus! In that case, we are forced to deal with three sets of rules". Further, upper-tier municipalities contain both regionally-managed and municipally-managed roadways, a tedious challenge that requires identification of the road type, connection with the correct level of government as well as the correct individual, and ongoing dialogue to proceed in improving the physical infrastructure around school zones.

One challenge that many study participants expressed was the distinct differences between urban form and cultures of mobility within and between large, sprawling regional municipalities, and how that presented many challenges in implementing a regional approach to ASST planning. For example, lower-tier municipalities that are located farther up north are comprised of primarily low-density and rural built form. As many of their students require busing and the residential communities are not considered 'walkable', the issue is of less importance to municipal stakeholders. Perhaps as a result, many of these municipalities have become reluctant to participate in ASST planning. Study participants agreed, however, that stakeholders have repeatedly observed many students not taking the provided school bus and instead, are driven to school by their parents: “The more northern municipalities think they aren't affected by this... They know all of their schools are bused so they dismiss this, but we know this isn't the case. They should be just as involved as any of us as we know the buses are empty in 
the morning as parents are driving their kids to school still for convenience. There is still traffic congestion there".

Within large suburban regional municipalities, widespread differences between cultures of mobility and ethnicities can exist between lower-tier municipalities. Varying languages, customs, and values greatly affect how regional ASST planning can be realized - reaffirming the need for a flexible and adaptive approach. Additional challenges towards regional ASST planning include the fragmented and nontransparent nature of many municipal initiatives, large school boards with an overwhelming number of individual schools, and lack of commitment from municipalities when they perceive themselves as one of many (staff turnover on the portfolio, lack of coordination, not a main priority).

Yet, regional government structure provides a highly appropriate setting for ASST planning and successful and impactful practice and strategies from around the world have previously been reported (Flanagan and Mitra, 2016). For example, within the Bay Area Region, California, US, the upper-tier regions offer opportunities for overarching strategy and encouragement, whereas lower-tier municipalities play supportive roles, introduce programs, and provide infrastructure improvements or modifications (Flanagan and Mitra, 2016). When describing the importance of regional leadership, one participant expressed: "We see the bigger picture, we don't come at it from a small perspective. If you are coming from the municipality, you only see what you have to do within your boundaries. We see the bigger picture and bring all the pieces together." However, as each lower-tier municipality is different from another - in terms of professional commitment, built form, demographics, and political council - regional strategy requires a level of flexibility to accommodate and facilitate municipal opportunities. 
Study participants discussed that regional governments present an opportunity for identifying more 'champions' of ASST planning in each municipality. The importance of the champion has been well documented in ASST and School Travel Planning literature, which indicate that large regional municipalities offer a greater number of employees and, thus higher probability that enough individuals would be interested and willing to play a role in regional ASST planning (Ward, et al., 2007).

\subsection{3 $\underline{\text { School Boards }}$}

Currently, the majority of school boards within the GTHA have not incorporated ASST planning into their mandated responsibilities, operations, or annual budgets. Study participants expressed that school boards have a limited understanding of their role within regional ASST planning, despite being completely aware of the associated societal problems relating to low rates of walking and cycling for school journeys. This disconnect is a substantial challenge towards implementation of ASST polices and related programs. Difficulties with the school board could be due to the multiple stakeholders that exist within them - from board level trustees, to operations and facilities, to teachers. Without the identification of a 'point person' or champion to create traction at each level of school board stakeholders, it can be extremely difficult to advance ASST programs and actions within the schools: "That is the hardest challenge - getting into the school boards. You need a go-to person, and without that, you can't get anything done. And it needs to be shared between the boards. They talk to the schools... and decide who needs it first and who needs it most". Further, school board administrators typically only review their specific school sites for built environment improvements, and do not consider the larger goals for a healthier and more active regional community. A final challenge that study participants related to school boards included the increasing variety of specialized programs that 
demand students to travel farther distances to attend specific schools - art programs, enrichment programs, and French language schools.

Similar to the parent community, study participants unanimously agreed that school board buy-in is critical for maintaining the sustainability of regional ASST planning. As one participant mentioned: "We can't do anything until the school board is fully engaged. Everything we do without the school board is a bandage solution".

Serving as the central source for reaching students and parents, the school boards offer opportunities to educate and facilitate discussion on the benefits associated with ASST and to implement school-specific programs. To enforce this, many school boards across the GTHA have developed an ASST Charter - a formal document that outlines roles, responsibilities, and expected coordination of each stakeholder. ASST Charters assist with improving the relationship with school boards, defining how each level of stakeholder within can play a role. Many study participants discussed that school boards feel they are perceived as a 'villain' in ASST planning, and that they are unfairly blamed for not taking more responsibility of the parents entering the school zone each morning and afternoon. By creating an ASST Charter, multiple regional municipalities have demonstrated the ability to disperse responsibility and fiscal responsibility to different stakeholders to effectively reduce individual liability, burden, and effort.

\subsection{Internal Factors}

The following internal themes have been categorized as influential factors that may emerge during governance processes, professional practice, and implementation of regional ASST planning. Each theme is a result of professional decision-making and municipal practice, and their associated challenges and opportunities can greatly affect the productivity of ASST initiatives and regional committees. These factors exist within the process of regional ASST 
planning and can be influenced and overcome by professionals. These themes include: 1)

Ownership by One Organization; 2) Multidisciplinary Stakeholder Groups; 3) Evaluation and Data Collection; and 4) Engagement of Elected Officials.

\subsubsection{Ownership by One Department or Organization}

Many international examples have demonstrated that a centralized approach to regional ASST planning is effective for increasing the sustainability and consistency of data collection, programming, funding, and stakeholder coordination (Flanagan and Mitra, 2016). Centralization, in this context, refers to the ownership and continuance of the program by one specific stakeholder. Although this practice is commonly attributed to as an important best practice, the associated challenges and opportunities of ownership have not been adequately assessed or scrutinized.

\subsubsection{The Burden of Program Ownership}

To many study participants, taking 'ownership' of regional ASST planning is closely linked to burdensome 'heavy lifting', risk and liability concerns, as well as the need to be overly prescriptive of the actions of other stakeholders. As regional ASST planning is considered a shared responsibility, some participants argued that one stakeholder maintaining complete ownership can negate the purpose of the multi-sector initiative: "I think we are stronger as a collaborative group rather than if someone was just owning it. We are a strong unit working together to achieve the same goal. It is much better when we come at it as a well organized and collaborative force." Further, single ownership may narrow the liability associated with the program to only one stakeholder - instead of dispersing risk equally between a group of partners. Many public sector stakeholders do not have the labour or financial resources to solely expand their professional portfolio to include ASST planning, resulting in overworked staff and a widely 
stretched budget line. Moreover, when maintaining ownership of a regional planning process, the leading stakeholder is required to set action items and work plans for other involved stakeholders.

Study participants discussed that by asserting that role, their relationship with other stakeholders could become highly perspective and that is not considered complementary to the collective and multidisciplinary nature of ASST planning: "Very few organizations are willing to step up and say what needs to happen and this is how we will get there. I understand why this happens, but I get frustrated when it prevents real work from happening."

\subsubsection{Determining which Stakeholder is Appropriate for Program Ownership}

Study participants expressed that it can be incredibly challenging to assign sole responsibility for regional ASST planning to one stakeholder, as the responsibility should be shared by multiple municipalities and other stakeholder groups. All stakeholder groups municipal planners, transportation services, public health, public works and infrastructure, district school boards, not-for-profit organizations - play a fundamental role in regional ASST planning, and contribute vastly different resources. When discussing this challenge, study participants recommended that each involved stakeholder should identify a senior staff member who is accountable for this initiative within their professional portfolio, and effectively collaborates with other senior staff to make productive and meaningful decisions.

\subsubsection{Balancing Ownership between Municipal and Regional Stakeholders}

Study participants discussed the challenges that emerge when a regional municipality begins to lead and retain ownership over ASST planning. When strong regional leadership is established, municipalities can begin to lose understanding and accountability of their roles and responsibilities. This can be challenging for effective planning, as the lower-tier municipalities 
are integral to the implementation of ASST interventions. Municipal staff are directly responsible for the realization of built environment improvements, as well as enacting and enforcing local policy.

One study participant, who is employed by a municipality, explained this further: "I don't know what my role is at all...maybe I will be more involved later but I am not there yet. My role just isn't clear to me. Maybe it is happening without me! That is a problem. I am invited to participate in everything but no one ever asks me to sit down and really do something tangible." Although ownership by each regional municipality is generally preferred by Metrolinx - to facilitate cross-jurisdiction collaboration and the ability to divert more resources towards the planning process - regional municipalities have limited power and authority in how interventions are implemented within each municipality. This theme demonstrates that maintaining an effective and accountable balance between regional and municipal ownership can be critical towards successful ASST planning. Moreover, the balance of leadership should be directly informed by context-specific considerations and transparent consultations of stakeholder preference within each regional municipality.

\subsubsection{Sustainability of the Program}

Strong, singular ownership of the program provides an opportunity for the leading stakeholder to clearly determine the necessary roles and responsibilities of diverse stakeholders, so that sustainable progress is maintained. Without defined responsibilities, consistency in efforts can wane and there are no perceived consequences for not completing tasks or attending meetings: "[owners of the program] need to enforce a structure that states: this is why we are here, this is what we are doing, this is your role, and you are letting the team down if you don't deliver... a significant percentage of the stakeholder group is not consistent...there is no harm if 
you don't show up." Ownership of the planning process fosters sustainability as there is single entity driving the initiative, connecting and following up with stakeholders, facilitating knowledge exchange, and ensuring stakeholders are disseminating consistent messaging or collecting reliable data. As discussed by one study participant: "The whole role of [the organization owning ASST planning] is to coordinate and centralize all the different groups working on school travel stuff. Not everyone was talking to everybody, so they tried to coordinate everyone and discover all of their data. We have the school boards, all the municipalities, police, crossing guards, Eco-Schools, student transportation consortia - it's a lot! They organize everyone together who looks at this from a different lens."

Moreover, study participants mentioned that when programs demonstrate longevity, sustainability, and stakeholder commitment, they are more likely to be attractive to municipal council for investment and policy enactment.

\subsubsection{Ease of Coordination}

When regional ASST planning is coordinated by one stakeholder, the process of maintaining an active regional committee, strategic plan, and dedicated staff member/champion (ASST planning coordinator) can become much simpler. Regional committees offer a forum for discussion between stakeholders, as well as facilitating knowledge exchange, opportunities for partnerships, decision-making, and strategic direction for the region. This practice that has been gradually implemented throughout the GTHA. Currently, four of six regional municipalities

(Peel, Hamilton, Halton, and York) maintain a formal regional ASST committee. By providing a central hub to formulate ideas and complete tangible action items - stakeholders feel more engaged, needed, and inspired. For one regional municipality, creating subcommittees was a major contributor for propelling the regional committee into a more meaningful and relevant 
experience for stakeholders. Study participants noted that many individuals that participate in regional ASST committees are passionate about the issue and regularly exceed their mandated portfolio in order to partake in ASST planning. These stakeholders have a desire to grow regional ASST planning, something which cannot be easily facilitated within broader committee meetings pertaining to active transportation planning.

To further centralize the coordination of efforts, one regional municipality (York Region) has employed a dedicated 'Active and Safe Routes to School Coordinator' position. As many involved stakeholders can only invest a small amount of time, effort, and funding into this work - it is significantly important for a champion to moderate and organize this central body of discussion. ASST planning coordinators can provide immense support and persistence in driving ASST planning from ideation (education and promotion) towards policy and practice. Study participants repeatedly expressed the value of this, explaining that regional ASST planning involves more work than simply one day events, and by having someone in this position, they can effectively delve deeper into the broader societal issues and facilitate culture change. Further, the process of updating and enforcing strategic planning documents becomes significantly more organized when led by one champion stakeholder. Coherent and relevant strategy plans are critical to the success of regional ASST planning as they dictate regional goals and objectives pertaining to ASST, connect ASST work with broader policy documents, and effectively outline the long-, medium-, and short-term priorities for regional planning.

\subsubsection{Multidisciplinary Stakeholder Groups}

Regional ASST planning approaches require the establishment of multi-sector and multidisciplinary stakeholder partnerships. Stakeholders - ranging from municipal departments, to advocacy groups, to school boards, to elected officials - provide multifarious possibilities for 
increasing revenue sources, building program identity, enhancing social and community capacity, avoiding overlap in activities, and the production of new ideas and programs for ASST initiatives (Macridis, et al., 2015). Scholarly literature suggests that ASST planning cannot be successfully implemented by one stakeholder group, and that without multiple partners to garner greater support - the program has a higher likeliness to fail (Macridis, et al., 2015, Mammen, et al., 2014b; Hinckson, et al., 2011; Ward, et al., 2007) Engaging a multidisciplinary stakeholder group can be highly valuable to regional ASST planning, however the approach is not without its associated challenges.

\subsubsection{Logistical Issues}

Large, multidisciplinary stakeholder groups may develop conflicts between differing agendas and mandates, opposing priorities, incompatible communication protocols and regulations, and when attempting to meet together as a large group. When more stakeholders are engaged in the ASST implementation process, there is a higher likeliness that each will follow distinctive organizational methods of defining and prioritizing projects, thus slowing progress and causing significant delays: "It can take months - or even years - to get programs approved, implemented, and properly measured."

\subsubsection{Finding a Common Vision}

When stakeholders attempt to find a common vision for ASST planning, they can face difficulties when consolidating their individual initiatives and policies into a larger program. Further, ASST planning can be delayed as each stakeholder undergoes an annual program review at differing times of the fiscal year. As experienced by one of the GTHA regional municipalities, a program review shifted one organization's priorities and reduced financial and human capital 
from ASST planning - causing group disruption when this major stakeholder partner could no longer engage in the planning process.

\subsubsection{Dilution of Knowledge}

Critical challenges arise when increasing the number of involved stakeholders, as this can dilute the committee's 'expert' knowledge of effective ASST planning. Stakeholder groups who are invited to join a potential regional ASST committee, may have mandates that moderately affect ASST - including environment awareness groups and by-law enforcement - however their lack of detailed knowledge on ASST planning and policy can lead to delayed progress as a whole. This delayed process is related to the need for stakeholder capacity-building, as well as ensuring each member understands the nuances and implications of planning for ASST. This can obstruct the advancement of regional committee initiatives as many committee members do not know how to appropriately and effectively contribute, albeit their enthusiasm: “They have good intentions and want to move things forward, but they don't have the knowledge base. That has hindered things...it is difficult because everyone thinks they know what they are talking about. They know broadly, but they don't understand specifics."

Stakeholder groups that 'know just enough' can contribute by providing general support in disseminating information through their communication channels and offering suggestions based on their perspective, however they cannot assist with critical tasks including setting goals and objectives for regional strategy and delivering innovative solutions. Moreover, stakeholder groups with limited knowledge typically do not have the ability or tools to collect detailed data on ASST - an essential component of sustainable regional strategy.

\subsubsection{Creating a Committee and Identifying Champions}


During the formation of a multidisciplinary stakeholder group, it can be challenging to identify stakeholder organizations within the regional municipality that could contribute and provide unique insights in the planning process. Various study participants explained the immense difficulties associated with pinpointing specific 'champions' to join regional stakeholder groups, and that the process of forming the initial group is more tedious and cumbersome than the later implementation tasks. This can be extremely deterring to regional municipalities that are considering the development of an ASST stakeholder group, but lack the sufficient resources to formally initiate and commit to the arduous process.

While several major challenges exist, a multitude of opportunities are presented when an ASST planning strategy is undertaken and coordinated at the regional level, and when a diverse set of stakeholders is engaged. Multidisciplinary groups offer a vast diversity in perspective, ideation, and problem solving.

\subsubsection{Range of Perspectives}

The multi-faceted nature of ASST planning offers opportunities for the program to be interpreted, and re-interpreted, through multiple angles and by multiple organizations with a region such as the GTHA. By distributing messaging through a diversity of perspectives, the initiative is likely to have a greater impact on students, parents, and communities. Study participants repeatedly expressed the invaluable strength of a collaborative and diverse stakeholder group: "When we look at all the folks involved, everyone is coming at it from a different perspective. My perspective is if I encourage people to walk and cycle than more people will be physically healthy. Other people are coming at it from the air pollution or safety side of things. And others think of this as a great way to get people moving to where they need to 
be...there are groups that can help and bring something different to the table...we need to stay open to doing things in new and innovative ways."

Remaining open and flexible to innovative problem solving, setting comprehensive strategic visions for stakeholders with common beliefs, and the stronger capacity to implement meaningful cross-jurisdictional programming were all noted as key opportunities of multidisciplinary groups. Further, engaging diverse stakeholders fosters a sense of "shared ownership over a shared problem". The decline of children walking and cycling to school can produce consequences that affect the entire community and inhabitants within the GTHA- traffic congestion and decreased air quality - which requires the ongoing attention and support of multisector and multi-jurisdictional stakeholders.

\subsubsection{6: Relationship Building}

Collaborative stakeholder connections developed and maintained through diverse regional groups can be built upon and reapplied in several different contexts. Study participants discussed how their involvement with ASST stakeholder groups has generated new relationships with unlikely community partners, and they have continued to utilize those connections in other aspects of their professional portfolio. When discussing this opportunity, one study participant explained the importance of building relationships to gain a more complete perspective on ASST planning: "It is all about building relationships with our community partners. Not only for ASST work but on other active transportation pieces. It was a great time collaborating and developing those new and existing relationships...it has built the foundation for later successes."

Diverse stakeholder groups yield widespread challenges and opportunities that affect both single and two-tier regional government structures. To establish deep roots for long-term sustainability and growth of regional ASST efforts, primary stakeholders must determine how 
'multidisciplinary' the stakeholder committee should become in order to adequately benefit themselves, their organization, and the greater community.

\subsubsection{Evaluation and Data Collection}

Collecting systematic and comprehensive data on ASST-related outcomes, to both monitor improvements to ASST rates and understand impact on students and the society, is a predominant issue of this planning practice and thus, provides both challenges and opportunities for professionals. As demonstrated in the US, the National Centre for Safe Routes to School enforces strict data collection requirements by each participating state in order for them to receive federal funding (Flanagan and Mitra, 2016). The program, launched in 2007, informs decision-making at the local, state, and national level and serves as a critical tool to monitor student commute patterns nationwide (NCSRTS, 2016). In October 2016, the Centre released a report entitled 'Trends in Walking and Bicycling to School from 2007-2014', revealing that since the introduction of a national, centralized data collection system in 2007, walking and cycling to school is more clearly measured and understood by professionals. The data collection process revealed that across the U.S.A., ASST levels have increased from 14\% to 17\% (NCSRTS, 2016). The report links this positive and upward trend to both sustainable funding and the maturing of school travel planning programs, however, the researchers note that without the centralized data collection system, the understanding of national ASST impact would not have so successfully occurred (NCSRTS, 2016).

\subsubsection{Lack of Incentive to Collect Data}

Data collection is a significant component of many international ASST initiatives, namely New Zealand and England (Flanagan and Mitra, 2016), however the practice has failed to find traction and longevity in Canada. Study participants discussed many challenges 
associated with data collection and why it has not been incorporated into their professional practice. Primarily, the critical challenge of collecting systematic data is the lack of a centralized system that is monitored, analyzed, and enforced by a level of government. The lack of incentive has resulted in limited interest, and the process of collecting data is perceived as more of a cumbersome task if one 'has extra time', rather than a critical means to identifying program progress: "We don't have enough time or resources to do that follow up measurement with schools... we don't really know if there has been a mode shift at all with specific schools... it has been more of a process pieces, we don't have any information on the outcomes." This is a detrimental barrier towards implementing systematic data collection, and requires support and intervention to facilitate a shift in thinking about future ASST planning. Additionally, participants mentioned they do not have the resources or the knowledge to adequately analysis their previously collected data, and that has resulted in a lack of momentum to collect more: "There is no board-wide mandate to collect data on this. To be honest, we have no drive to this. Individual schools might be doing it but it's not very sophisticated."

\subsubsection{Haphazard Approach of Current Data Collection}

As municipalities across the GTHA do not collect systematic and comparable ASST data due to lack of resources and incentive, current data collection typically falls upon the shoulders of not-for-profit organizations and individual schools. As such, data is collected sporadically by volunteers that are interested in contributing to ASST advancements within their local community: "Some volunteers get together and count how many kids take the bus to school and see how much time it takes the bus to unload or load. But this data has never really been looked at...it isn't sophisticated." This approach towards data collection is a direct result of limited regional coordination and the absence of sustainable funding. Study participants recommended 
that a standardized framework for data collection comprised of regional key performance indicators, as well as dedicated funding, should be considered when developing a regional ASST planning strategy.

The scope of existing efforts was noted as a key challenge by study participants meaning practitioners can normally only collect data on the few pilot project schools engaged in an annual school travel planning program (6-10 per year on average), which results in both limited comparative data and sporadic samples over the following years. Further, the lack of experience of individuals conducting ongoing data collection has led to simple and uncomprehensive methods, instruments, and tools. Current methods measure mode share and produce traffic count levels, however there is a notable lack of original and innovative questions pertaining to student perceptions of ASST, evaluation of interventions and programs, costs of implementation, increased fitness or friendship levels, or perhaps, awareness of one's personal environmental impact.

The challenges associated with data collection are widespread and difficult to overcome, however this practice presents a significant opportunity to collect comparable and standardized data to evaluate the impact of regional ASST planning and inform future active transportation policymaking at a regional level.

\subsubsection{Evidence-Based Decision Making}

Study participants repeatedly discussed the urgent need for updated ASST rates, as well as a more coherent ASST baseline figures, in order to effectively appeal to government for program and infrastructure funding. By having reliable data on current ASST levels, stakeholders can use the figures to influence decision-makers to invest money or approve policy statements relating to ASST planning. According to study participants, these approvals are imperative for 
expanding data collection scope, conducting follow-up assessments, and ensuring overall program sustainability. Through the development of regional key performance indicators, professionals can better identify where improvements in the planning process are necessary. Not only does this improve efficiency of implementation, but maintains transparency and accountability of the planning process. As one study participant discussed, "We need to do some really good baselining to understand this. What is the mode share right now? We know it is approximately some number from Metrolinx...but we need to have updated numbers and set some realistic targets. Maybe we need to set smaller goals for the region... is $60 \%$ of kids walking and cycling actually realistic? Then we need to break it off into annual increments that are measured by KPI measurements, and everyone has to leave the room with a clear set of marching orders to collect data."

Notwithstanding the challenges or opportunities related to systematic data collection, understanding the outcomes of regional ASST planning is a significant next step for the GTHA. By doing this, the GTHA can move forward from simply implementing process pieces, and begin considering the implications towards different levels of stakeholders and their respective regional municipalities.

\subsubsection{Engagement of Elected Officials}

The role of power in the planning process is a perpetual area of debate and discussion for academics and professionals alike. The engagement of elected officials in regional ASST planning, and the political power and influence associated with their stature, is no exception. Research conducted by Flyvbjerg (1998) revealed how elected representatives can use power to alter and depart from the formal planning process. He discusses that power has a clear tendency to dominate rationality, and that power can both define and create new physical, economic, and 
social realities for planners (Flyvbjerg, 1998). Moreover, political advisors are confronted with a wider spatial complexity and context than typical stakeholders, meaning it is difficult for them to overcome influence from their minister's constituency, greater institutions, and political networks (Albrechts, 2003). The political approach to decision-making is unique, as it entails a process complete with different rationale, actors, logic, and consequences (Albrechts, 2003). As such, elected officials are not simple and autonomous stakeholders.

\subsubsection{Navigating the Political Landscape}

The introduction of politics in regional planning for ASST was a critical challenge identified by study participants. The nature of elected officials can present substantial obstacles when stakeholders attempt to advocate for new policy or program investment. Although elected officials can express their personal support towards initiatives during regional meetings, their actions are required to reflect the desires of the local constituency. As many parents, particularly in the suburban municipalities, may not support ASST - political support for ASST planning from elected officials is often not present. Further, study participants also discussed frustrations associated with the electoral system, "If it is an election year, it is a disaster. They completely undermine the entire process. Politicians don't allow for a 'park a block and walk' initiative because that is resident houses and they control the streets. It always is interesting timing."

\subsubsection{Ambiguous Implementation Power}

Involving elected officials within the ASST planning process can cause confusion for other stakeholders, as many seem unclear on how responsibility transitions downwards from political support into staff implementation. While school board trustees and/or municipal councilors can express public commitment towards ASST planning, study participants expressed they were unsure if elected officials had the authority to substantially alter the professional 
mandate of municipal and regional staff: "I know the trustees are always supportive of the messaging, but how does that actually filter down? I have no idea." When considering this disconnect, study participants questioned whether elected officials provided value to the regional ASST progress or not.

\subsubsection{Access to Political Perspective and Experience}

Through engaging elected officials, opportunities emerge in their ability to mobilize, build alliances, present unlikely connections, and reach acceptable consensus (Albrechts, 2003). Study participants discussed the importance of a political perspective within the planning process. Having extensive experience with governance and bureaucracy, elected officials contribute wisdom pertaining to operational issues, recognizing the correct stakeholders to connect with, and the inner intricacies that politicians and boards face when implementing something. As one study participant expressed: "The trustees have been taking that step and making some really good links for us, it provides us with a list of individual schools that I can go in and provide school travel planning education." Further, elected officials are a representation of a greater resident community, offering a strong understanding of the cultural nuances of people who inhabit the area, as well as their associated concerns about ASST.

\subsubsection{Ability to Mobilize Institutions and Communities}

Elected officials can effectively bring media and resident attention to regional ASST planning, establishing the program as a strong and relevant priority for the regional municipality - albeit current policies, plans, and previous identified priorities. This opportunity can quickly, as well as publically, propel regional ASST planning from ideation and idealism towards regional implementation. This speaks closely to Flyvbjerg's interpretation of elected officials, as 
the greater the power, the greater the freedom and less need for understanding how reality is 'really' constructed (Flyvbjerg, 1998).

\subsection{Discussion}

This research study revealed significant insights into the challenges and opportunities that professional stakeholders face when planning for ASST. Moreover, these insights reveal how a regional approach to planning could be designed to accommodate and alleviate these challenges, while providing the appropriate resources and guidance to realize opportunities. This research discovered that more challenges exist, than opportunities, when planning for ASST. This is consistent with the experience of other international areas that have developed regional approaches. Regions including Metro Vancouver, Canada; the Bay Area, US; and Auckland Region, New Zealand have reported difficulties in coordinating a regional strategy for improving ASST rates - particularly in regard to differing stakeholder interests, sustainable funding sources, and identifying and empowering a champion to lead efforts (Flanagan and Mitra, 2016). That being said, overcoming these challenges was potentially less cumbersome for each case study, as each has a governance structure that includes only one regional municipality which is further divided into numerous municipalities (Flanagan and Mitra, 2016). Conversely, the GTHA is unique in which the defined area represents regional traffic flow and transit service by Metrolinx, and has no direct governing body. As examined previously in this research, the GTHA is comprised of six regional municipalities, which are further divided into a multitude of individual municipalities. As such, the GTHA cannot easily implement international best practices in regional planning for ASST as the identified strategies do not always fit within the area's governance structure. Yet, the driving forces and rationale behind each best practice are significantly important for GTHA stakeholders to learn from. 
The findings from this research study reveal that the GTHA would benefit from a regional approach to ASST planning. That being said, the proposed approach must account for various stakeholders with different levels of interest, as well as ensuring any ambiguity regarding authority, roles, responsibilities, and implementation power is clarified. Moreover, the research indicates that the regional approach should be primarily flexible in nature, however data collection methods and key performance indicators should be standardized at the regional level to generate comparable and systematic data.

This study revealed that a regional approach is well complemented when an Active and Safe Routes to School coordinator is employed by one stakeholder, or through a partnership between multiple stakeholders. This ensures each stakeholder has a central point of contact for ASST-related inquires, and that the program progresses sustainably. Further, the coordinator can dedicate the sufficient time needed to untangle logistical conflicts, approach new stakeholders to become involved in ASST planning, coordinate regional committees, and assign roles and responsibilities to diverse stakeholders. This finding is consistent with international case study regions, many of which have dedicated regional ASST divisions and/or employees.

Presently, four regional municipalities within the GTHA have been successful in establishing a regional committee for ASST. This research supports this approach by discussing the value of regional committees, however challenges their current structure. Study participants repeatedly mentioned that a successful regional approach to ASST planning should offer opportunities at regional committee meetings to produce creative and tangible deliverable, as well as chances to build meaningful relationship with other stakeholders. Overall, the proposed regional approach within the GTHA should reflect international best practices, while still accounting for the context-specific requirements of local ASST stakeholders. This will ensure 
that the regional approach effectively facilitates local ownership in ASST planning, so that stakeholders can continue to successfully plan for ASST. 


\section{CONCLUSION}

This research study, complementary to an ongoing strategic planning process for the GTHA, is the first investigation of the challenges and opportunities that professional stakeholders face within both upper-tier regional municipalities and lower-tier municipalities when planning for improved ASST rates in this region. Contrary to other research studies which have analyzed one specific population, including the qualitative analysis of STP facilitators conducted by Mammen and colleagues (Mammen, et al., 2015), this examination included opinions from a diversity of stakeholders, including region-level public health departments, municipal urban planners, transportation services, not-for-profit organizations, environmental sustainability professionals, school board representatives, and elected officials.

This research illustrates a clear picture where challenges and opportunities currently and commonly exist. The discussion aimed to examine gaps in regional ASST planning, recognize barriers towards implementation, and identify where further support and facilitation by higherlevel strategy and/or intervention is required.

Many forces, both external and internal to the planning process, were identified by study participants as having significant influence in the outcomes of regional ASST planning. External themes - Parent Acceptance of the Program, Regional Government Structure, and School Boards - each presented multiple challenges and opportunities that are outside the scope of ASST planning professionals and can be extremely difficult to navigate or overcome.

This research discussed internal themes in depth, to identify where specific challenges and opportunities emerge when integrating the theory of ASST planning into professional practice and implementation. These themes included: Ownership by One Organization, Multidisciplinary Stakeholder Groups, Evaluation and Data Collection, and Engagement of 
Elected Officials. The findings illustrate how each associated challenge can detrimentally affect the progress of ASST stakeholders. Further, it provides details of specific experiences when identified challenges have had significant influence in the success of regional ASST planning. Within this research, opportunities are discussed as capacities or outlets that ASST stakeholders have applied to overcome the associated challenges. Further, additional opportunities have been identified where ASST stakeholders believe future success and advancement of the program could be found, if challenges were alleviated. The following table outlines the internal themespecific challenges and opportunities that were identified through this research study.

Table 6.1

\begin{tabular}{|c|c|c|}
\hline Internal Theme & Challenge & Opportunity \\
\hline \multirow{4}{*}{$\begin{array}{l}\text { Ownership by One } \\
\text { Organization }\end{array}$} & The Burden of Program Ownership & Sustainability of the Program \\
\hline & Determining which Stakeholder is & Ease of Coordination \\
\hline & Balancing Ownership between & \\
\hline & Municipal and Regional Stakeholders & \\
\hline \multirow{4}{*}{$\begin{array}{l}\text { Multidisciplinary } \\
\text { Stakeholder Groups }\end{array}$} & Logistical Issues & Range of Perspectives \\
\hline & Finding a Common Vision & Relationship Building \\
\hline & Dilution of Knowledge & \\
\hline & $\begin{array}{l}\text { Creating a Committee and Identifying } \\
\text { Champions }\end{array}$ & \\
\hline \multirow{2}{*}{$\begin{array}{l}\text { Evaluation and Data } \\
\text { Collection }\end{array}$} & Lack of Incentive to Collect Data & $\begin{array}{l}\text { Evidence-Based Decision } \\
\text { Making }\end{array}$ \\
\hline & $\begin{array}{l}\text { Haphazard Approach of Current Data } \\
\text { Collection }\end{array}$ & \\
\hline \multirow[t]{2}{*}{$\begin{array}{l}\text { Engagement of Elected } \\
\text { Officials }\end{array}$} & Navigating the Political Landscape & $\begin{array}{l}\text { Access to Political Perspective } \\
\text { and Experience }\end{array}$ \\
\hline & Ambiguous Implementation Power & $\begin{array}{l}\text { Ability to Mobilize Institutions } \\
\text { and Communities }\end{array}$ \\
\hline
\end{tabular}


The limitations of this research are consistent with the broader limitations of undertaking a qualitative research study. This includes inconsistent timing of data collection, lack of observational methods (data cannot be replicated easily), and heavy reliance on instrumentation for measurement. As the qualitative interviews were conducted between June and August in 2016, many stakeholders were unable to participate due to prior commitments and vacations. Further, as this study was informed by a qualitative approach, with no supplementary quantitative analysis, the findings cannot be easily reproduced to validate precision and accuracy. Additionally, the research only provided analysis of five out of six municipal regions within the GTHA. Halton region declined to participate in the interview process on the basis that it was unnecessary and unhelpful to their progress.

This research offers few recommendations towards improvement of regional ASST planning, due to the context of limited systematic research on this topic. Yet, the research provides practitioners and policymakers with a detailed understanding of the challenges and opportunities of regional planning for ASST, offering further opportunities for them to build upon and devise context-specific strategies and unique interventions to overcome the identified difficulties.

Planning for active and sustainable school travel at the regional level is complicated. Yet, it is exceptionally important for the continued health of both people and place. Regional planning is critically important for cross-jurisdictional collaboration and for understanding the effectiveness and value of publicly funded programs. Further, regional planning offers meaningful opportunities for stakeholder capacity building, shared learning, and productive partnerships. This type of work can seem cumbersome, and even impossible, by stakeholders something that requires the funding, labour, and time that many do not have. However, solutions 
emerge within effective and responsive regional ASST planning - creating approaches that facilitate openness, collaboration, as well as adapting to differences in both built form and culture. This is imperative, and yet, this can be achieved through creation and adoption of progressive regional ASST planning strategy within the GTHA. 


\section{Appendix: Interview Guide}

\section{ROLES AND RESPONSIBILITIES}

1. Can you describe your professional role as it relates to ASST planning/implementation?

\section{CURRENT ASST PLANNING PRACTICE \& PROCESSES}

2. What are your region's key goals and objectives for ASST?

3. Tell me about the current ASST programming/initiatives in your region that are specifically meant to encourage students to walk/cycle to and from school?

4. Which, if any, of the abovementioned programming and/or initiatives are coordinated at a regional level?

5. How you are measuring ASST success in your region?

6. Do you know of any other organization(s) who are collecting Key Performance Indicator (KPI) data related to school travel within your region (example: a school, a school board, the student transportation consortia, public health, or a municipal department)?

\section{STAKEHOLDERS AND RELATIONSHIPS}

7. Please describe the nature of the relationship between municipalities and other organizations that are involved in the ASST planning process in your region?

8. Is there a specific organization that is taking ownership for / leading ASST planning/implementation in your region?

9. Who are the current ASST stakeholders within your region, and how are they contributing to planning and/or implementation in your region?

10. Which stakeholders regularly attend regional ASST meetings?

11. What methods are you currently using to bring stakeholders to the table? Please provide as much detail as possible.

12. Who are the potential stakeholders that are not actively involved in the ASST planning/implementation process in your region, but you'd like to see on board?

\section{CONCLUSIONS}

13. In your professional opinion, what would you like to see happen with ASST planning in your region?

14. Is there anything you would like to add or expand on? 


\section{REFERENCES}

1. Active and Safe Routes to School - About. (2017). Retrieved from http://www.saferoutestoschool.ca/about

2. Albrechts, L. (2003). Reconstructing Decision-Making: Planning Versus Politics. Planning Theory, 2(3).

3. Atkins Limited. (2010). An evaluation of the 'Travelling to School Initiative' programme: final report. Atkins Ltd., Birmingham, UK

4. Auckland Transport. (2013). Community Transport Evaluation Report for 2012/2013

5. Aurora. Council. Infrastructure \& Environmental Services. (2013). School Travel Planning and Traffic Management. Report No. IEs13-056.

6. Baslington, H. (2008). School Travel Plans: Overcoming Barriers to Implementation. Transport Reviews, 28(2), 239-258.

7. Biddix, P. (2009). Qualitative Research Design. Retrieved from https://researchrundowns.com/qual/qualitative-research-design/

8. Boarnet, M., Anderson, C., Day, K., Mcmillan, T., \& Alfonzo, M. (2005). Evaluation of the California Safe Routes to School legislation. American Journal of Preventive Medicine, 28(2), 134-140.

9. Buliung, R., Mitra, R., \& Faulkner, G. (2009). Active school transportation in the Greater Toronto Area, Canada: An exploration of trends in space and time (1986-2006).

Preventive Medicine, 48, 507-512.

10. Buliung, R., Faulkner, G., Beesley, T., \& Kennedy, J. (2010). School Travel Planning: Mobilizing School and Community Resources to Encourage Active School Transportation. Journal of School Health, 81(11), 704-712.

11. Cairns, S. \& Newson, C. (2006) Making school travel plans work. Effects, benefits and success factors at English schools. Wasted Miles, Wasted Money, Paper presented at the 30th UK Transport Conference 2006, University of Nottingham, Nottingham, UK, April, pp. 95-113.

12. Chillon, P., Evenson, K., Vaughn, A., \& Ward, D., 2011. A systematic review of intervention for promoting active transportation to school. International Journal of Behavioral Nutrition and Physical Activity. 8, 10-27

13. Coffey, A., \& Atkinson, P. (1996). Making sense of qualitative data: complementary research strategies. Sage Publications, Incorporated, London. 
14. Cooper, A., Wedderkopp, N., Wang, H., Andersen, L., Froberg, K., \& Page, A., (2006). Active travel to school and cardiovascular fitness in Danish children and adolescents. Med. Sci. Sports Exerc. 38, 1724-1731.

15. Darbyshire, P. (2005). Multiple methods in qualitative research with children: More insight or just more? Qualitative Research, 5(4), 417-436.

16. Education Act and School Inspections Act (1996). Great Britain, Department for Education and Employment.

17. Flanagan, C., \& Mitra., R. (2016). International Best Practices in Regional Planning for School Travel. Report prepared for Metrolinx.

18. Flyvbjerg, B. (1998). Rationality and power: Democracy in practice. Chicago: University of Chicago Press.

19. Glaser, G., \& Strauss, L., (1967). The Discovery of Grounded Theory: Strategies for Qualitative Research, Chicago, Aldine Publishing Company

20. Green Communities Canada. (2010). Review of International School Travel Planning Best Practices. Retrieved from the Green Communities Canada website: http://www.saferoutestoschool.ca/sites/default/files/STP\%20Intl\%20Best $\% 20$ PracticeUpdate-Apr\%2010.pdf

21. Guliani, A., \& Mitra, R. (2015). Gender-based differences in school travel mode choice behaviour: Examining the relationship between the neighbourhood environment and perceived traffic safety. Journal of Transport \& Health, 2(4), 502-511.

22. HASTe BC: Action Showcase Map (2017). Retrieved from http://www.hastebc.org/action-showcase

23. Hinckson, E., Garrett, N., \& Duncan, S. (2011). Active commuting to school in New Zealand Children (2004-2008): A quantitative analysis. Preventive Medicine, 52(5), 33236.

24. Hodgson, F., \& Tight, M. (1999) Raising awareness of transport issues: the potential to bring about behavioural change? International Journal of Sustainable Development and World Ecology, 6(4), pp. 281-292

25. Janssen, I., \& LeBlanc, A. (2010). Systematic review of the health benefits of physical activity and fitness in school-aged children and youth. International Journal of Behavioral Nutrition and Physical Activity.

26. Lambiase, M., Barry, H., \& Roemmich, J. (2010). Effect of a simulated active commute to school on cardiovascular stress reactivity. Med. Sci. Sports Exerc. 42, 1609-1616. 
27. Larouche, R., Saunder, T., Faulkner, G., Colley, R., \& Tremblay, M. (2012). Associations between active school transport and physical activity, body composition and cardiovascular Fitness: a systematic review of 68 Studies. J. Phys. Act. Health.

28. Larsen, K., Gilliland, J., \& Hess, P. (2012). Route-based analysis to capture the environmental influences on a child's mode of travel between home and school. Ann. Assoc. Am. Geogr. 102, 1-18.

29. Larsen, K., Buliung, R., \& Faulkner, G. (2013). Safety and school travel: how does the environment along the route relate to safety and mode choice? Transp. Res. Rec. 2327, 9 18

30. Mackett, R., Lucas, L., \& Paskins, J. (2003) The Effectiveness of Initiatives to Reduce Children's Car Use. Association for European Transport.

31. Macridis, S., \& Bengoechea, E. (2015). Adoption of Safe Routes to School in Canadian and the United States Contexts: Best Practices and Recommendations. Journal of School Health, 85(8).

32. Mammen, G., Stone, M., Buliung, R., \& Faulkner, G. (2014a). School travel planning in Canada: Identifying child, family, and school-level characteristics associated with travel mode shift from driving to active school travel. Journal of Transport \& Health, 1(4), 288294.

33. Mammen, G., Stone, M., Faulkner, G., Ramanathan, S., Buliung, R., O’Brien, C., \& Kennedy, J. (2014b). Active school travel: An evaluation of the Canadian school travel planning intervention. Preventive Medicine, 60, 55-59.

34. Mammen, G., Stone, M., Buliung, R., \& Faulkner, G. (2015). "Putting school travel on the map": Facilitators and barriers to implementing school travel planning in Canada. Journal of Transport \& Health, 2(3).

35. Marshall, C., \& Rossman, G. (1989). Designing qualitative research. Newbury Park, CA: Sage Publications.

36. McDonald, N. (2008). Household interactions and children's school travel: the effect of parental work patterns on walking and biking to school. J. Transp. Geogr. 16 (5), 324331

37. McDonald, N., \& Aalborg, A. (2009). Why parents drive children to school: implications for safe routes to school programs. J Am Plann Assoc. 75(3):331-342.

38. Mcdonald, N., Deakin, E., \& Aalborg, A. (2010). Influence of the social environment on children's school travel. Preventive Medicine, 50. 
39. McMillan, T. (2007). The relative influence of urban form on a child's travel mode to school. Transp. Res. Part A: Policy Pract. 41 (1), 69-79.

40. Metrolinx. (2008). The Big Move: Transforming Transportation in the Greater Toronto and Hamilton Area. Retrieved from the Metrolinx website: http://www.metrolinx.com/thebigmove/Docs/big move/TheBigMove 020109.pdf

41. Metrolinx. (2012). Stepping it Up Report. Retrieved from the Metrolinx website: http://www.metrolinx.com/en/projectsandprograms/schooltravel/SteppingItUpReportEN G.pdf

42. Metrolinx. (2013a). Barriers and Enablers Report. Retrieved from the Metrolinx website: http://www.metrolinx.com/en/projectsandprograms/schooltravel/ASST Barriers and En ablers-Full Report EN.pdf

43. Metrolinx. (2013b). Active and Sustainable School Transportation Strategy Roadmap Report. Retrieved from the Metrolinx website: http://www.metrolinx.com/en/projectsandprograms/schooltravel/ASST Strategy Roadm ap Report EN.pdf

44. Metrolinx. (2014). The costs and benefits of school travel planning projects in Ontario, Canada. Retrieved from the Metrolinx website: http://www.metrolinx.com/en/projectsandprograms/schooltravel/Costs and Benefits of School Travel Planning Projects EN.pdf

45. Metrolinx. (2015a). School Travel in the GTHA: A Report on Trends. Retrieved from the Metrolinx website: http://smartcommute.ca/wpcontent/uploads/2016/02/School Travel Trends GTHA En.pdf

46. Metrolinx. (2015b). Bike to School Week Summary Report 2015. Retrieved from the Metrolinx website: http://www.bikemonth.ca/BTSW15 Report.pdf

47. Metropolitan Transportation Commission: Federal, State, and Local. (2017). Retrieved from http://mtc.ca.gov/our-work/invest-protect/investment-strategiescommitments/protect-our-climate/bay-area-safe-routes

48. Mitra, R., \& Buliung, R. (2014). The influence of neighborhood environment and household travel interactions on school travel behavior: an exploration using geographically- weighted models. J. Transp. Geogr. 36, 69-78.

49. Mitra, R., Faulkner, G., Buliung, R., Stone, M. (2014). Do parental perceptions of the neighbourhood environment influence children's independent mobility? Evidence from Toronto, Canada. Urban Studies, 51(16), 3401-3419.

50. Mitra, R., \& Buliung, R. (2015). Exploring differences in school travel mode choice behaviour between children and youth. Transport Policy, 42, 4-11. 
51. Moodie, M., Haby M., Galvin, L., Swinburn, B., \& Carter, R. (2009). Costeffectiveness of active transport for primary school children - Walking School Bus program. International Journal of Behavioral Nutrition and Physical Activity. 6:63.

52. National Center for Safe Routes to School [NCSRTS] (2012). "The decline of walking and bicycling". Retrieved June 21, 2013 from http://guide.saferoutesinfo.org/introduction/the decline of walking and bicycling.cfm

53. National Centre for Safe Routes to School [NCSRTS] (2016). Trends in Walking and Bicycling to School from 2007 to 2014.

54. Neuwelt, P., \& Kearns, R. (2006) Health benefits of walking school buses in Auckland, New Zealand: perceptions of children and adults, Children, Youth and Environments, 16(1), pp. 104-120.

55. NICE Public Health Collaborating Centre (2008) Promoting physical activity for children: Review 5-Active travel interventions.

56. Nueman, W., \& Robson, K. (2012). Basics of social research: qualitative and quantitative approaches. (2nd CDN ed.). Toronto, Canada: Pearson Canada Inc.

57. Panter, J., Jones, A., van Sluijs, E., \& Griffin, S. (2010). Neighborhood, route, and school environments and children's active commuting. Am. J. Prev. Med. 38 (3), 268-278.

58. ParticipACTION (2016). Report Card on Physical Activity for Children and Youth.

59. Peddie B., \& Somerville C. (2005) Travel Behaviour Change through School Travel Planning: Mode Shift and Community Engagement - Results from 33 Schools in Victoria. Department of Infrastructure, Transport Research Forum. Melbourne, Australia.

60. Rennie, K., Johnson, L., \& Jebb, K. (2005). Behavioural determinants of obesity. Best Practice \& Research Clinical Endocrinology \& Metabolism

61. Rothman, L., Buliung, R., Macarthur, C., To, T., \& Howard, A. (2013). Walking and child pedestrian injury: a systematic review of built environment correlates of safe walking. Injury Prevention,20(1), 41-49.

62. Staunton, C., Hubsmith, D., \& Kallins, W. (2003). Promoting Safe Walking and Biking to School: The Marin County Success Story. Am J Public Health American Journal of Public Health, 93(9), 1431-1434.

63. Schlossberg, M., Greene, P., Phillips, P., Johnson, B., \& Parker, B. (2006). School trips: Effects of urban form and distance on travel mode. J. Am. Plan. Assoc. 72 (3), 337-346. 
64. TravelWise Schools. (2017). Retrieved from https://at.govt.nz/cycling-walking/ schooltravel/travelwise-schools/

65. Timperio, A., Ball, K., \& Salmon, J. (2006). Personal, familial, social and environmental correlates of active commuting to school. Am. J. Prev. Med. 30, 45-51.

66. van der Ploeg, H., Merom, D., Corpuz, G. \& Bauman, A. (2008). Trends in Australian children traveling to school 1971-2003: Burning petrol or carbohydrates? Preventive Medicine, 46(1): 60-62

67. Ward, D., Linnan, L., Vaughn, A., Neelon, B., \& Martin, S., (2007) Characteristics associated with US Walk to School programs. International Journal of Behavioral Nutrition and Physical Activity.

68. Weigand, L. (2008). The Effectiveness of Safe Routes to School and Other Programs to Promote Active Transportation to School (Rep.). Centre for Urban Studies, University of Portland.

69. Wilson, E., Wilson, R., \& Krizek, K. (2007). The implications of school choice on travel behavior and environmental emissions. Transp. Environ. 12, 506-518. 


\section{Glossary of Key Terms}

ASST: Active and Sustainable School Travel. Active transportation is the most sustainable transportation option and includes walking, cycling, rolling or other human powered modes of mobility - encouraging daily exercise and reducing wear and tear on public infrastructure. Sustainable transportation also includes public transit and school buses - the use of multipleoccupancy vehicles to reduce emissions.

GTHA: Greater Toronto and Hamilton Area. The region is comprised of two single tier municipalities- Toronto and Hamilton, and four upper-tier municipalities: Durham Region, York Region, Halton Region and Peel Region.

STP: School Travel Planning. This model, created by Green Communities Canada, is used to promote active and sustainable modes of school travel for students, families and staff in Canadian communities. It is delivered through a School Travel Facilitator and consists of 5 key approaches that are widely acknowledged to encourage walking and cycling: Engineering, Education, Enforcement, Encouragement, and Evaluation.

SRTS: Safe Routes to School. This is an international program, however is typically attributed to the United States of America. This program promotes walking and biking to school using education and incentives. It is designed to decrease traffic and pollution, while increasing the health and wellbeing of children and the greater community. 